\title{
The Research of Project Quality Management Model Based on Lean Construction
}

\author{
Han Yike ${ }^{a}$, Wang Jianbin ${ }^{b}$ \\ School of management, Xi'an University of Architecture and Technology, Xi'an710055, China \\ ayikehan123@163.com, bwajb@xauat.edu.cn,
}

Key words: lean construction; project quality management; quality management model

\begin{abstract}
Derived from the manufacturing, lean construction is a new kind of project management model. Lean thinking is built into the in the process of construction quality management, the difference between the traditional construction mode and lean construction are analyzed. From two aspects of external control and internal management, a new project quality management model based on lean construction is built.
\end{abstract}

\section{Introduction}

The formation of building products is a complex process, from a single project and sub-project to hidden project, which involves a lot of quality problems in the process of building products formation. There are some problems as follows existing in the traditional construction project quality management. Firstly, quality management system is imperfect, lacking of perfect qualification review mechanism and supervision mechanism. On the other hand, the quality of building materials and construction technology examine lax, etc. Secondly, the construction enterprises lack of quality management consciousness and legal consciousness. The method and the process of construction is not in accordance with the quality standard. Thirdly, construction workers personal quality is low, most of them without professional training, only by working experience in construction, easy to cause operation is not standard. Fourthly, construction material quality also has question, the quality difference among the same specifications construction material is huge. The circulation of nonconforming product in the market directly threat to the quality of building products. Finally, the lack of effective supervision for construction market, and the lack of market access system.

At present, Application of lean construction in China is less, but it has been widely research and application in some areas and abroad, such as Denmark's MT Hojgaard company implemented the lean construction in the project, the results confirmed that the profit of implement lean construction project is higher, and ensured construction working environment, What is important is that lean construction reduced the incidence of quality accident ${ }^{[1]}$. Above all, lean construction has a significant impact on the project, it’s very necessary to implement lean construction.

\section{The concept of lean construction}

Lean construction derived from the lean production in manufacturing. Lean production is a producing idealized model which is aiming to manufacture timely, eliminate failure, eliminate waste in order to zero defects, zero inventory. At present, lean production have been widely used in manufacturing, and have had a positive effect, and it reduce production costs and improve production efficiency. Similar to the manufacturing, construction building products completes the construction through a series of steps. If the construction process of building products can be seen as a special manufacturing process, the application of lean production in construction projects is lean construction.

Based on the production management theory, guided by lean thinking, lean construction is a new project management model. It re-designs the project management process for the purpose of handing over projects which is premised on ensuring quality, the shortest duration, consuming 
minimal resources ${ }^{[2]}$.

\section{The comparison of quality management mode between lean construction and traditional management}

The traditional management project mode is given priority to with design and construction stage, and considered the construction unit, construction units and supervision units as the main body. Design stage quality management mainly includes the quality standard control and design work control. In the construction stage, construction units base on construction contract, design drawings and technical specification, follow the principle of prevention first, active control, strengthening the inspection, carry out quality control in the whole of the project construction process, ensure the project to design using the standard, to fulfill the requirements ${ }^{[3]}$. Under the traditional model, judging whether the quality of the project is eligibility only bases on the sampling results or submission results, which does not fully reflect the quality of construction projects. Therefore, this method is not sufficient to be relied on.

Lean production quality management primarily take self-test, self-divided, self-recording and self-control activities, focusing on the culture of quality consciousness of each employee. Also establish "3N" thought, namely, don't build substandard goods, don’t accept substandard goods and don't deliver substandard goods, and solves the quality problems in the early stages in order to control quality defects and errors deferred ${ }^{[4]}$. Lean construction does not reduce quality control steps, such as determining the quality objectives, designing quality control, quality control of the implementation, quality control of materials and equipment and so on. The difference is that lean construction puts a greater emphasis on full participation and overall control, actively eliminate the processes which do not produce value. The difference of management mode between lean construction and traditional construction is as shown in Table 1.

Table1. The difference of management mode between lean construction and traditional construction

\begin{tabular}{|c|c|c|}
\hline & Lean construction & Traditional construction \\
\hline Building goal & Eliminating waste, create value & $\begin{array}{l}\text { Complete the contract } \\
\text { requirements }\end{array}$ \\
\hline Supervisor mode & Flexible & Stiffness \\
\hline Product quality & Zero defect, high quality & Can t guarantee \\
\hline Project organization & Compact & Large \\
\hline Cooperation degree & $\begin{array}{l}\text { Attaches importance to the } \\
\text { long-term cooperation, } \\
\text { respect for employees }\end{array}$ & $\begin{array}{l}\text { Only focus on contract } \\
\text { and its interests }\end{array}$ \\
\hline Inventory level & $\begin{array}{l}\text { High material utilization, } \\
\text { less waste }\end{array}$ & Inventory, waste is serious \\
\hline Design methods & Parallel & Serial \\
\hline Information sharing & $\begin{array}{l}\text { Information transparency, } \\
\text { convenient communication }\end{array}$ & $\begin{array}{l}\text { Information block, } \\
\text { not circulation }\end{array}$ \\
\hline User relationships & Meet customer demand & $\begin{array}{l}\text { Cannot be combined with } \\
\text { customer demand }\end{array}$ \\
\hline
\end{tabular}

\section{Build the management mode of lean construction}

Quality management of project involves contractors subcontracting enterprises, on-site construction workers and so on. The traditional quality management process is quite confused, because lack of communication between the various parties and management responsibility is not clear which lead to low efficiency and quality problem. To change the traditional quality management ideas and models, it is necessary to apply lean thinking to the construction quality, and balance external monitoring and internal management.

External monitoring mainly includes government inspection agencies, relevant laws and regulations, construction supervision. The main part of the internal management consists of the support layer, management layer, executive layers. The support layer mainly builds information sharing platform, stream analysis is mainly through the analysis of value activities of quality management activities in order to find wasteful behavior and eliminate waste to improve 
construction quality. Management layer is mainly analyzing problems among the contractor enterprises, subcontracting enterprises, labor subcontracting enterprises and on-site construction workers. Executive layer mainly uses the idea of lean construction to realize management. Management framework is as shown in figure 1.

\section{Conclusion}

In this day and age, the concept of "quality is life" has been around. The quality of construction products has attracts a wide spread attention. To achieve the desired goals, it is necessary to improve the quality assurance system, strengthen the design unit, supervision unit and government regulation. At the same time use the concept and methods of lean construction, grab from the source of quality problems, attaches great importance to the quality management of the project, and study economic efficiency of quality control to realize the unification of project quality and economic benefits.
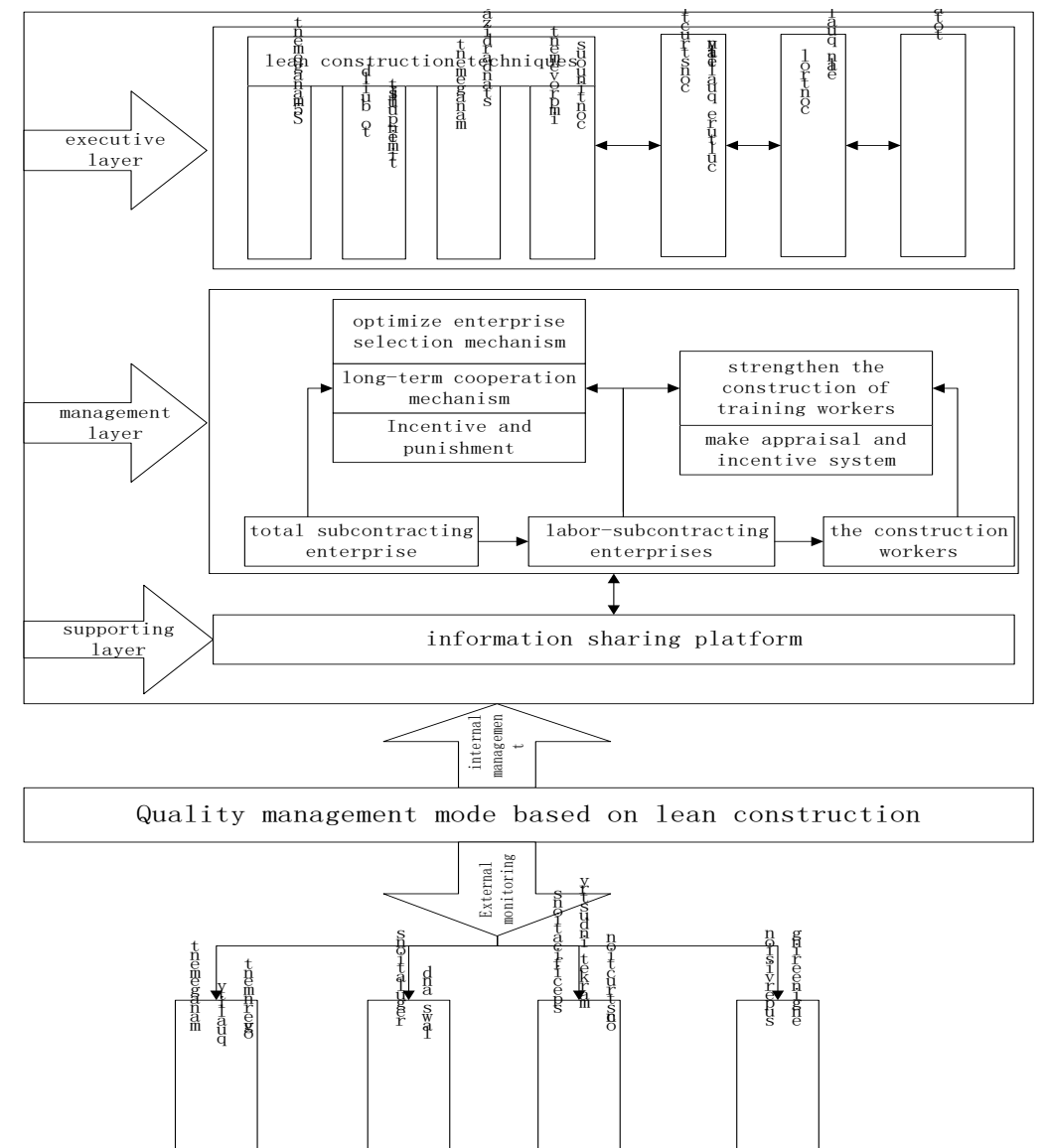

Figure 1 project management model framework based on lean construction

\section{References}

[1] Mikkel Andreas, Thomassen, Dag Sander, etc. Experience and results from implementing lean construction in a large Danish contracting firm[A]. Proceedings IGLC- 11, USA, 200

[2] Luis F.Alarcon and Rodrigo Calderòn. Implementing Lean Production Strategies in Construction Companies, Construction Research 2003:1 8

[3] Zhao Rui-feng, Chen Shao-wei. The research of project quality management and quality control[J]. Shanxi Architecture, 2007, 33(6): 245-246.

[4] Zhu Bin-mei, Liu Xiao-jun, Wang Zhi-hui. New thinking based on lean construction of the three elements of project quality, cost, time-limit[J]. Building Economy, 2007(11):13-15. 